\title{
ISOLADOS DE ESTREPTOMICETOS NO CRESCIMENTO E NUTRIÇÃO DE MUDAS DE TOMATEIRO' ${ }^{1}$
}

\author{
Ana Cristina Fermino Soares ${ }^{2}$, Carla da Silva Sousa ${ }^{2}$, Marlon da Silva Garrido ${ }^{3}$, Francisco de Sousa Lima ${ }^{2}$
}

\begin{abstract}
ESTREPTOMICETE ISOLATES IN TOMATO

SEEDLINGS GROWTH AND NUTRITION

Streptomycetes are known for producing secondary metabolites, such as antibiotics and extracellular enzymes, that act in the degradation of complex and recalcitrant molecules, playing an important role in composting processes. Thus, to evaluate the effect of soil inoculation and incubation with streptomycete isolates, in the initial growth stage of tomato seedlings, an experiment was conducted in a completely randomized design, with six streptomycete isolates and a non-inoculated control. The soil was inoculated and incubated for 20 days, before planting. After 30 days, the seedlings were collected for determination of seedling height, stem diameter, dry weight of shoots and roots, and nutrients accumulation in shoots. The streptomycete isolates promoted significant increments in the growth and nutrients contents of tomato seedlings. It is suggested that the 35-days incubation period of the inoculated soil, before planting, promotes the time necessary for the streptomycetes to act in the mineralization of soil organic matter, providing nutrients for plants growth.
\end{abstract}

KEY-WORDS: Actinomycetes; growth promotion; Lycopersicum esculentum (L.) Santa Clara.

\section{INTRODUÇÃO}

O consumo de hortaliças tem aumentado, devido à maior conscientização da população, em busca de uma dieta alimentar mais rica e saudável. Desse modo, o desenvolvimento de sistemas de cultivo com hortaliças, visando à otimização da produtividade, tem exigido, dos agricultores, esforços no sentido de reduzir, ou até mesmo eliminar, deficiências do setor produtivo, como problemas nutricionais e fitossanitários das mudas (Montezano \& Peil 2006). A produção de mudas de hortaliças constitui-se em uma das etapas mais importantes do sistema produtivo,

\section{RESUMO}

Os estreptomicetos são conhecidos pela produção de metabólitos secundários, como antibióticos e enzimas extracelulares, que atuam na degradação de moléculas complexas e recalcitrantes, desempenhando papel importante nos processos de compostagem. Neste sentido, com o objetivo de avaliar o efeito da inoculação e incubação de solo com isolados de estreptomicetos, no crescimento inicial de mudas de tomateiro, foram avaliados seis isolados de estreptomicetos, mais o controle não inoculado. O solo foi inoculado com os estreptomicetos e incubado por 20 dias, antes do plantio. Após 30 dias, as mudas foram coletadas para determinação da altura, diâmetro do caule, massa seca da parte aérea e raízes e acúmulo de nutrientes na parte aérea. Os isolados de estreptomicetos promoveram incrementos significativos no crescimento e acúmulo de nutrientes, nas mudas de tomateiro. Acredita-se que a incubação do solo, por 35 dias, antes do plantio, garanta o tempo necessário para que os estreptomicetos atuem na mineralização da matéria orgânica, disponibilizando nutrientes para o crescimento das plantas.

PALAVRAS-CHAVE: Actinomicetos; promoção de crescimento; Lycopersicum esculentum (L.) Santa Clara.

influenciando, diretamente, o desempenho final das plantas, nos canteiros da produção, tanto do ponto de vista nutricional quanto do ciclo produtivo da cultura (Carmello 1995). Mudas mal formadas debilitam e comprometem todo o desenvolvimento da cultura, aumentando seu ciclo e levando a perdas na produção (Guimarães et al. 2002).

O tomate é a mais importante hortaliça cultivada no Brasil, embora, do ponto de vista agronômico, seja uma cultura complexa e de risco econômico elevado, principalmente em virtude da susceptibilidade a diversos fitopatógenos (Filgueira 2000). O uso de agroquímicos, nos sistemas de produção agrícola,

1. Trabalho recebido em maio/2009 e aceito para publicação em nov./2010 (nº registro: PAT 6139/ DOI: 10.5216/pat.v40i4.6139). 2. Universidade Federal do Recôncavo da Bahia, Centro de Ciências Agrárias, Ambientais e Biológicas, Cruz das Almas, BA, Brasil.E-mails: ferminosoares@gmail.com, cssagro@yahoo.com.br, fsousalima@yahoo.com.br.

3. Fundação Universidade Federal do Vale do São Francisco, Campus de Ciências Agrárias, Petrolina, PE, Brasil. E-mail: garridoms@yahoo.com.br. 
tem gerado problemas, com o desenvolvimento de resistência dos patógenos aos produtos utilizados e impactos ambientais negativos, devido ao amplo espectro de ação destes produtos, atingindo organismos não-alvos e causando riscos à saúde humana e animal. Neste sentido, a utilização de micro-organismos com ação de biocontrole e/ou promoção de crescimento vem sendo apontada como alternativa viável para sistemas de produção agrícola ecológica e economicamente sustentáveis (Compant et al. 2005).

A família Streptomycetaceae compreende um importante grupo de bactérias provenientes, principalmente, do solo, pertencentes à classe Actinobacterias. Estes micro-organismos são procariotos, gram-positivos, com formação de micélio e esporos (Padilha 1998). O gênero mais abundante é o Streptomyces (70-90\%) das colônias desenvolvidas em meio de cultura sólido, seguido de Nocardia (5-30\%) e Micromonospora (1-15\%) (Otoniano et al. 2006). O solo é o habitat natural da maioria dos estreptomicetos, por oferecer condições apropriadas para o seu crescimento e proliferação. Além disto, suas características físicas e químicas são os principais fatores que afetam a quantidade e diversidade destes micro-organismos (Katsifas et al. 2000).

Durante o processo de compostagem, os estreptomicetos atuam na degradação de moléculas complexas e recalcitrantes, especialmente celulose, lignocelulose, xilana e lignina, presentes em abundância na biomassa vegetal (Petrosyan et al. 2003, Ding et al. 2004, Peláez 2006). Além da atuação na decomposição da matéria orgânica, estes micro-organismos apresentam grande potencial como agentes de controle biológico de fitopatógenos (Thirup et al. 2001, Hoster et al. 2005), devido à produção de inúmeros metabólitos bioativos, incluindo antibióticos, sideróforos e enzimas com ação antimicrobiana (Shahidi Bonjar et al. 2004). O presente trabalho teve como objetivo avaliar o efeito da inoculação e incubação de solo com isolados de estreptomicetos, no crescimento e nutrição de mudas de tomateiro.

\section{MATERIAL E MÉTODOS}

\section{Isolamento de estreptomicetos}

O experimento foi conduzido em condições de casa-de-vegetação do Centro de Ciências Agrárias, Ambientais e Biológicas da Universidade Federal do Recôncavo da Bahia, em Cruz das Almas (BA), de setembro a novembro de 2008. Os isolados de estreptomicetos avaliados foram provenientes de solo rizosférico de bananeira (Musa sapientum) (AC103), maracujazeiro (Passiflorae edulis f. flavicarpa) (AC-147), olerícolas (AC-92), solo sob jaqueira (Artocarpus integrifolia) (AC-26 e AC-29) e solo com adubação verde incorporada (AC-95).

Para isolamento dos estreptomicetos, foi obtida uma suspensão, por meio da mistura de $10 \mathrm{~g}$ de solo e $90 \mathrm{~mL}$ de solução salina estéril ( $\mathrm{NaCl} 0,85 \%$ ), que foi mantida sob agitação, por 30 minutos, à temperatura ambiente, em mesa agitadora orbital. Alíquota de $1 \mathrm{~mL}$ desta suspensão foi transferida para tubos de ensaio contendo $9 \mathrm{~mL}$ de solução salina estéril $(\mathrm{NaCl}$ 0,85\%), procedendo-se uma diluição seriada da suspensão $\left(10^{2}\right.$ a $\left.10^{5}\right)$. Após este procedimento, foi retirada uma alíquota de $50 \mathrm{~mL}$ das diluições $10^{2}$ e $10^{3}$, que, com o auxílio de alça de Drigalsky, foi distribuída em placas de Petri contendo meio de cultura amido caseína ágar sólido.

Para se obter o isolamento de actinomicetos, além da utilização de meio de cultura seletivo amido caseína ágar, foi realizado o pré-tratamento das amostras de solo, que consistiu no aquecimento destas a $40^{\circ} \mathrm{C}$, por 6 horas, para inibir o crescimento de bactérias, e na adição de ciclohexamida, na concentração $100 \mathrm{mg} / \mathrm{mL}$ no meio de cultura, para inibir o crescimento de fungos. As placas foram incubadas à temperatura de $28^{\circ} \mathrm{C}$, por um período de 21 dias, em câmara de crescimento tipo B.O.D. Foram realizadas observações diárias, sendo as colônias de estreptomicetos isoladas, purificadas, codificadas e transferidas para placas de Petri contendo meio de cultura AGS sólido. As colônias de actinomicetos do gênero Streptomyces são pequenas pulverulentas ou velutinas, com micélio aéreo de diferentes tonalidades, e produzem pigmentos solúveis, sendo bem distintas das colônias de actinomicetos dos gêneros Frankia, Micromonospora, Nocardia, Rhodococcus e Thermoactinomyces.

\section{Obtenção de inóculo de estreptomicetos}

Para obtenção de inóculo, os isolados foram multiplicados, em meio de cultura AGS sólido, e incubados, por um período de 10 dias, em câmara de crescimento tipo B.O.D., a $28^{\circ} \mathrm{C}$. Após este período, foram adicionados $15 \mathrm{~mL}$ de água destilada e esterilizada em cada placa de Petri contendo as culturas dos micro-organismos crescidas e, com o auxílio de 
alça de platina, foi feita a raspagem das colônias. A concentração da suspensão obtida foi ajustada para densidade ótica $\mathrm{A}_{560}=0,4$, em espectrofotômetro.

Produção de enzimas extracelulares, ácido indolacético e capacidade de solubilização de fosfatos

A produção de amilase pelos estreptomicetos foi determinada conforme metodologia de Coon et al. (1957), onde os micro-organismos foram cultivados em meio de cultura ágar amido, constituído de $0,2 \%$ de amido solúvel, por 10 dias, a $28 \pm 2^{\circ} \mathrm{C}$. Foi realizada a adição de $10 \mathrm{~mL}$ de solução de lugol às placas e a produção da enzima foi detectada pela descoloração do meio, em torno da colônia, indicando a hidrólise do amido.

Para avaliar a produção de quitinase, foi utilizado o método sugerido por Renwick et al. (1991), onde os estreptomicetos foram cultivados em meio de cultura de sais minerais (Tuite 1969), contendo quitina coloidal como única fonte de carbono. Após 10 dias de cultivo, a atividade quitinolítica dos isolados foi detectada pela formação de um halo hialino, em torno das colônias crescidas.

A produção de celulase e xilanase pelos estreptomicetos foi determinada conforme Lewis (1988), onde os micro-organismos foram cultivados em meio de cultura de sais minerais (Tuite 1969), suplementado com celulose ou xilana, como fonte de carbono, respectivamente, por 10 dias, a $28 \pm 2^{\circ} \mathrm{C}$. Após este período, foram adicionados $10 \mathrm{~mL}$ de solução de vermelho congo ( $0,5 \%)$, por 15 minutos, e, em seguida, $10 \mathrm{~mL}$ de solução de $\mathrm{NaCl}(1 \mathrm{M})$, por 30 minutos. A formação do halo de coloração alaranjada, em torno das colônias crescidas, indicou a atividade celulolítica e xilanolítica dos isolados.

A produção de lípases foi avaliada pelo cultivo dos estreptomicetos, em meio de cultura contendo Tween 80, como fonte de carbono (Sierra 1957), seguida da incubação das placas a $28 \pm 2^{\circ} \mathrm{C}$, durante 10 dias. A produção da enzima foi detectada pela formação de halo branco difuso, ao redor das colônias crescidas.

A produção de ácido indolacético pelos estreptomicetos foi determinada conforme metodologia de Bric et al. (1991). Os isolados de estreptomicetos foram cultivados em meio de cultura triptocaseína de soja $10 \%$, acrescido de $5 \mathrm{~mL}$ de L-triptofano, cobertos com uma membrana de nitrocelulose, por 10 dias, a $28 \pm 2^{\circ} \mathrm{C}$. Após este período, as membranas foram removidas e saturadas com solução de Salkowski, durante 30 minutos. Os isolados que formaram halo avermelhado na membrana foram considerados produtores de ácido indolacético.

Para avaliar a capacidade de solubilização de fosfatos, foi utilizado método proposto por Katznelson \& Bose (1959), onde os estreptomicetos foram cultivados em meio de cultura triptocaseína de soja $10 \%$, acrescido de $\mathrm{CaHPO}_{4}$, e, em seguida, as placas foram incubadas a $28 \pm 2^{\circ} \mathrm{C}$, por 10 dias. Após este período, a solubilização de fosfatos pelos estreptomicetos foi detectada pela formação de halo claro, em torno das colônias.

Inoculação e incubação do solo com estreptomicetos

O experimento foi desenvolvido em delineamento inteiramente casualizado, sendo avaliados seis isolados de estreptomicetos, descritos anteriormente, mais a testemunha, em 10 repetições, com uma planta/repetição. A composição química do solo utilizado no experimento é apresentada na Tabela 1.

O solo foi esterilizado por autoclavagem, a $120^{\circ} \mathrm{C}$, durante 1 hora, e, em seguida, foi realizada a adição de $20 \mathrm{~mL}$ do inóculo contendo propágulos dos estreptomicetos, para cada $400 \mathrm{~cm}^{3}$ de solo. A testemunha foi constituída por solo não inoculado, irrigado com água destilada. Após a inoculação, foi feita a homogeneização dos solos correspondentes a cada isolado de estreptomiceto, com o auxílio de uma espátula de madeira esterilizada. Em seguida, estes foram incubados em sacos de polietileno com capacidade para $20 \mathrm{~L}$, por 20 dias, a $28^{\circ} \mathrm{C}$ (Sousa et al. 2009). Após incubação, o solo foi transferido para sacos com capacidade para $400 \mathrm{~cm}^{3} \mathrm{e}, \operatorname{logo}$ após, foi

Tabela 1. Caracterização química do solo utilizado no experimento (Cruz das Almas, BA, 2008).

\begin{tabular}{lr}
\hline \multicolumn{1}{c}{ Característica } & Valor \\
\hline $\mathrm{pH}\left(\mathrm{água}^{-1: 2,5)}\right.$ & 6,40 \\
$\mathrm{P}\left(\mathrm{mg} \mathrm{dm}^{-3}\right)$ & 27,00 \\
$\mathrm{Na}^{+}\left({\left.\mathrm{cmol} \mathrm{dm}^{-3}\right)}^{-3}\right.$ & 0,04 \\
$\mathrm{~K}^{+}\left(\mathrm{cmol}_{\mathrm{c}} \mathrm{dm}^{-3}\right)$ & 61,00 \\
$\mathrm{Ca}^{2}\left(\mathrm{cmol} \mathrm{dm}^{-3}\right)$ & 3,30 \\
$\mathrm{Mg}^{+2}\left(\mathrm{cmol}_{\mathrm{c}} \mathrm{dm}^{-3}\right)$ & 1,50 \\
$\mathrm{Al}^{+3}\left(\mathrm{cmol}_{\mathrm{c}} \mathrm{dm}^{-3}\right)$ & 0,05 \\
$\mathrm{H}+\mathrm{Al}\left(\mathrm{cmol}_{\mathrm{dm}} \mathrm{dm}^{-3}\right)$ & 1,81 \\
$\mathrm{M} . \mathrm{O} .\left(\mathrm{g} \mathrm{kg}^{-1}\right)$ & 16,08 \\
$\mathrm{~S}\left(\mathrm{cmol}_{\mathrm{c}} \mathrm{dm}^{-3}\right)$ & 4,69 \\
$\mathrm{~T}\left(\mathrm{cmol}_{\mathrm{c}} \mathrm{dm}^{-3}\right)$ & 6,50 \\
$\mathrm{~V}(\%)$ & 92,15 \\
\hline
\end{tabular}


realizada a semeadura, colocando-se três sementes de tomateiro 'Santa Clara' em cada saco. Uma semana após a germinação, realizou-se o desbaste, deixando-se uma planta por saco.

Durante o experimento, a umidade do solo foi mantida em $70 \%$ da capacidade de campo, por meio de irrigações diárias, com água destilada.

As mudas foram coletadas 30 dias após a germinação das sementes, avaliando-se a altura das plantas, com auxílio de régua milimetrada, e diâmetro do caule, à altura dos cotilédones, com auxílio de paquímetro digital. A parte aérea e as raízes das plantas foram coletadas, lavadas em água destilada e colocadas para secar em estufa com ventilação forçada, a $65^{\circ} \mathrm{C}$, até atingir massa constante (3 dias). Após a secagem em estufa, determinou-se a massa seca da parte aérea e do sistema radicular. Foi realizada a moagem e, em seguida, digestão nitroperclórica da parte aérea das plantas, para a determinação dos nutrientes $\mathrm{P}^{+}, \mathrm{K}^{+}, \mathrm{Ca}^{++}, \mathrm{Mg}^{++}, \mathrm{Fe}^{++}, \mathrm{Cu}^{++}$e $\mathrm{Mn}^{++}$(Embrapa 1999).

Os dados foram submetidos a análise de variância e, logo após, foi realizada comparação das médias, pelo teste de Scott \& Knott, ao nível de 5\% de probabilidade, utilizando-se o programa estatístico Sisvar (Ferreira 2000).

\section{RESULTADOS E DISCUSSÃO}

Observou-se que os isolados de estreptomicetos não diferiram entre si. Entretanto, proporcionaram incremento significativo no crescimento das mudas de tomateiro, em relação ao controle não inoculado (Tabela 2). O incremento proporcionado foi de até $71 \%$ na altura das plantas, $73 \%$ no diâmetro do caule, $266 \%$ na produção de massa seca na parte aérea e $300 \%$ na produção de massa seca nas raízes das mudas de tomateiro, cultivadas no solo inoculado e incubado com os isolados AC-26, AC-92 e AC-29, respectivamente, em relação ao controle.
Estudo desenvolvido por Sousa et al. (2009) demonstrou que a inoculação de substrato comercial orgânico, com os mesmos isolados de estreptomicetos utilizados neste trabalho, promoveu o crescimento e a melhoria nutricional das mudas de tomateiro. Entretanto, os resultados foram ainda mais expressivos quando foi realizada a inoculação seguida da incubação do substrato 20 dias antes do plantio, em relação aos tratamentos em que houve o plantio das sementes imediatamente após a inoculação com os estreptomicetos, sem um período prévio de incubação. Tal período está, possivelmente, associado ao ciclo de vida do estreptomiceto e ao período necessário para a produção de enzimas extracelulares e degradação dos compostos presentes no substrato.

O ciclo de crescimento típico de um estreptomiceto envolve a germinação de esporos, formando hifas filamentosas, que crescem na superfície do substrato (fonte de nutriente). A hifa forma ramificações, que dão origem ao micélio denso (fase vegetativa). Posteriormente, ocorre a segunda fase de crescimento aéreo, acompanhada da produção de metabólitos secundários, como os antibióticos. Nesta fase, as hifas crescem para fora do micélio, algumas vezes formando estruturas helicoidais, e dão origem à cadeia de esporos, que iniciam, novamente, o ciclo vegetativo (Goriely \& Tabor 2003). As hifas ramificadas penetram no substrato, metabolizando fontes orgânicas de nutrientes, pela ação de enzimas extracelulares como polissacarídeos (amido, pectina, quitina e celulose) e compostos aromáticos (Padilha 1998).

Os resultados obtidos no trabalho desenvolvido por Sousa et al. (2009) e no presente estudo demonstram que, possivelmente, o período de incubação do solo ou substrato, por 20 dias, proporcionou tempo hábil para que os estreptomicetos, que possuem elevada capacidade de degradação de moléculas complexas, através da produção de enzimas extracelulares como celulase, xilanase, amilase

Tabela 2. Crescimento das mudas de tomateiro cultivadas em solo inoculado e incubado com isolados de estreptomicetos (Cruz das Almas, BA, 2008).

\begin{tabular}{lcccc}
\hline Isolado & Altura da planta $(\mathrm{cm})$ & $\begin{array}{c}\text { Diâmetro do caule } \\
(\mathrm{mm})\end{array}$ & $\begin{array}{c}\text { Massa seca da parte } \\
\left.\text { aérea }(\mathrm{g} \text { planta })^{-1}\right)\end{array}$ & $\begin{array}{c}\text { Massa seca das raízes } \\
\left.(\mathrm{g} \mathrm{planta})^{-1}\right)\end{array}$ \\
\hline Controle & $11,7 \mathrm{~b}^{*}$ & $3,0 \mathrm{~b}$ & $0,12 \mathrm{~b}$ & $0,04 \mathrm{~b}$ \\
AC-26 & $20,0 \mathrm{a}$ & $5,2 \mathrm{a}$ & $0,42 \mathrm{a}$ & $0,16 \mathrm{a}$ \\
AC-29 & $17,1 \mathrm{a}$ & $4,4 \mathrm{a}$ & $0,42 \mathrm{a}$ & $0,18 \mathrm{a}$ \\
AC-92 & $17,9 \mathrm{a}$ & $4,9 \mathrm{a}$ & $0,42 \mathrm{a}$ & $0,15 \mathrm{a}$ \\
AC-95 & $16,7 \mathrm{a}$ & $4,7 \mathrm{a}$ & $0,46 \mathrm{a}$ & $0,16 \mathrm{a}$ \\
AC-103 & $17,8 \mathrm{a}$ & $4,5 \mathrm{a}$ & $0,41 \mathrm{a}$ & $0,16 \mathrm{a}$ \\
AC-147 & $18,9 \mathrm{a}$ & $4,8 \mathrm{a}$ & $0,38 \mathrm{a}$ & $0,17 \mathrm{a}$ \\
\hline
\end{tabular}

* Médias seguidas da mesma letra, na vertical, não diferem entre si, pelo teste de Scott \& Knott, a 5\% de probabilidade. 
Tabela 3. Produção de enzimas extracelulares, ácido indolacético e capacidade de solubilização de fosfatos pelos isolados de estreptomicetos (Cruz das Almas, BA, 2008).

\begin{tabular}{|c|c|c|c|c|c|c|c|}
\hline \multirow{2}{*}{ Isolado } & \multicolumn{5}{|c|}{ Enzimas extracelulares } & \multirow{2}{*}{$\begin{array}{c}\text { Produção } \\
\text { de ácido } \\
\text { indolacético }\end{array}$} & \multirow{2}{*}{$\begin{array}{c}\text { Solubilização } \\
\text { de fosfato }\end{array}$} \\
\hline & Quitinase & Celulase & Xilanase & Amilase & Lipase & & \\
\hline AC-26 & + & + & - & + & + & + & - \\
\hline $\mathrm{AC}-29$ & + & + & + & + & + & + & - \\
\hline AC -92 & - & - & + & + & + & + & + \\
\hline AC-95 & + & + & + & + & + & + & + \\
\hline AC-103 & + & + & + & + & + & + & + \\
\hline AC-147 & + & + & + & + & + & + & + \\
\hline
\end{tabular}

Nota: (+) presença da atividade; (-) ausência da atividade.

e lipase (Tabela 3), pudessem atuar na decomposição das substâncias orgânicas, promovendo a mineralização da matéria orgânica presente no solo. Como consequência deste processo, possivelmente, houve a liberação de nutrientes, que, após a germinação das sementes, estavam prontamente disponíveis para serem absorvidos pelas raízes, favorecendo o crescimento e o estado nutricional das plantas, como pode ser constatado pelo acúmulo de fósforo, potássio, cálcio, magnésio, ferro, manganês e cobre, na parte aérea das mudas de tomateiro cultivadas no solo inoculado e incubado por 20 dias com os isolados de estreptomicetos (Tabela 4).

Observou-se que o isolado AC-92 proporcionou incremento de $400 \%$ no acúmulo de P. Mudas de tomateiro cultivadas no solo inoculado e incubado com o isolado AC-147 apresentaram aumento de $281 \%$ no acúmulo de $\mathrm{K}$, quando comparadas com as mudas controle. Houve incremento de $544 \%$ e $471 \%$ no acúmulo de $\mathrm{Ca}$ e $\mathrm{Cu}$, respectivamente, nas mudas de tomateiro cultivadas em solo inoculado e incubado com o isolado AC-26, em relação às mudas do tratamento controle. O isolado AC-29 promoveu aumento de $468 \%$ e $460 \%$ no acúmulo de $\mathrm{Mn}$ e $\mathrm{Mg}$, na parte aérea das mudas. Observou-se incremento de até $432 \%$ no acúmulo de $\mathrm{Fe}$, nas mudas de tomateiro, promovido pelo isolado AC-95.

Além da produção de enzimas extracelulares, a promoção de crescimento das mudas de tomateiro pode ser atribuída à produção de ácido indolacético, uma substância reguladora de crescimento vegetal, para a qual todos os isolados de estreptomicetos avaliados apresentaram, in vitro, a capacidade de produção (Tabela 3). Esta substância funciona como reguladora de crescimento dos vegetais, sendo responsável pela divisão, expansão e diferenciação de células e tecidos vegetais, principalmente das raízes (Teale et al. 2006), além de apresentar influência direta na germinação de sementes (Tsavkelova et al. 2007). A síntese de fitohormônios, por bactérias associadas a plantas, é uma das formas mais importantes de interação planta-bactéria, causando modificações na morfologia das raízes, que proporciona o desenvolvimento do sistema radicular e, consequentemente, a melhor exploração do solo, tornando as plantas menos susceptíveis ao déficit hídrico e à escassez de nutrientes (Spaepen et al. 2007).

$\mathrm{O}$ efeito proporcionado pelos estreptomicetos às mudas de tomateiro pode, também, estar associado à capacidade de solubilização de fosfato, conforme

Tabela 4. Acúmulo de nutrientes na parte aérea das mudas de tomateiro cultivadas em solo inoculado e incubado com isolados de estreptomicetos (Cruz das Almas, BA, 2008).

\begin{tabular}{|c|c|c|c|c|c|c|c|}
\hline \multirow{2}{*}{ Isolado } & $\mathrm{P}$ & $\mathrm{K}$ & $\mathrm{Ca}$ & $\mathrm{Mg}$ & $\mathrm{Cu}$ & $\mathrm{Mn}$ & $\mathrm{Fe}$ \\
\hline & \multicolumn{4}{|c|}{ (mg g ${ }^{-1}$ planta $)$} & \multicolumn{3}{|c|}{$\left(\mathrm{mg} \mathrm{g}^{-1}\right.$ planta $)$} \\
\hline Controle & $0,2 \mathrm{~b}^{*}$ & $2,7 \mathrm{~b}$ & $0,9 \mathrm{~b}$ & $0,5 \mathrm{~b}$ & $16,7 \mathrm{c}$ & $5,03 \mathrm{c}$ & $21,1 \mathrm{~d}$ \\
\hline AC-26 & $0,9 \mathrm{a}$ & $9,8 \mathrm{a}$ & $5,8 \mathrm{a}$ & $2,7 \mathrm{a}$ & $95,4 \mathrm{a}$ & $27,3 \mathrm{a}$ & $93,5 \mathrm{a}$ \\
\hline AC-29 & $0,9 \mathrm{a}$ & $10,2 \mathrm{a}$ & $4,6 \mathrm{a}$ & $2,8 \mathrm{a}$ & $91,2 \mathrm{a}$ & $28,4 \mathrm{a}$ & $85,8 \mathrm{~b}$ \\
\hline AC-92 & $1,0 \mathrm{a}$ & $8,2 \mathrm{a}$ & $5,6 \mathrm{a}$ & $2,6 \mathrm{a}$ & $73,9 \mathrm{~b}$ & $18,5 \mathrm{~b}$ & $85,6 \mathrm{~b}$ \\
\hline AC-95 & $0,5 \mathrm{~b}$ & $9,4 \mathrm{a}$ & $5,2 \mathrm{a}$ & $2,5 \mathrm{a}$ & $75,2 \mathrm{~b}$ & $17,7 \mathrm{~b}$ & $112,2 \mathrm{a}$ \\
\hline AC-103 & $0,8 \mathrm{a}$ & $8,9 \mathrm{a}$ & $4,8 \mathrm{a}$ & $2,3 \mathrm{a}$ & 85,9 a & $25,9 \mathrm{a}$ & $69,5 \mathrm{c}$ \\
\hline AC-147 & $0,8 \mathrm{a}$ & $10,3 \mathrm{a}$ & $4,2 \mathrm{a}$ & $1,8 \mathrm{a}$ & $74,5 \mathrm{~b}$ & $18,8 \mathrm{~b}$ & $71,5 \mathrm{c}$ \\
\hline
\end{tabular}

* Médias seguidas da mesma letra, na vertical, não diferem entre si, pelo teste de Scott \& Knott, a 5\% de probabilidade. 
também demonstrado, in vitro, pelos isolados de estreptomicetos (Tabela 3). Segundo Jain \& Jain (2007), entre os micro-organismos solubilizadores de fosfato, os actinomicetos apresentam destaque especial, principalmente por sobreviverem em uma variedade de solos e serem produtores de uma infinidade de compostos bioativos, que podem beneficiar o crescimento das plantas. Os principais mecanismos envolvidos na solubilização de fosfatos pelos micro-organismos são a produção de ácidos orgânicos, síntese de enzimas fosfatases e excreção de prótons.

O período necessário para a incubação do solo, possivelmente, varia de acordo com a espécie de micro-organismo avaliado, considerando-se que, quanto maior a diversidade metabólica que este apresentar, mais rápido e completo será o processo de mineralização dos compostos orgânicos presentes no solo.

Além da atividade metabólica dos estreptomicetos, outros aspectos devem ser considerados, como a população destes micro-organismos no solo, que deve ser suficiente para que ocorra seu estabelecimento no ambiente rizosférico. Além disto, estes necessitam ter competência rizosférica, ou seja, capacidade de colonizar o sistema radicular e sobreviver no solo ou rizosfera, na presença da microbiota nativa (Compant et al. 2005). Segundo estes autores, a falta de competência rizosférica afeta a interação micro-organismo/planta, sendo uma das principais causas responsáveis pelo insucesso de trabalhos desenvolvidos com micro-organismos agentes de biocontrole e promotores de crescimento em nível de campo.

Este trabalho demonstrou a capacidade de isolados de estreptomicetos de promover o crescimento e a melhoria do estado nutricional de plantas, especificamente de mudas de tomateiro, em solo estéril. Trabalhos futuros deverão estudar e elucidar os mecanismos de ação destes micro-organismos no solo e na planta e seu potencial de promoção de crescimento e melhoria nutricional de outras culturas de interesse agronômico, avaliando, também, a capacidade competitiva, em relação à microbiota nativa, em substrato e solo não estéril.

\section{CONCLUSÕES}

1. A inoculação e incubação do solo com os isolados de estreptomicetos proporcionou incrementos significativos no crescimento e nutrição das mudas de tomateiro.
2. Todos os isolados de estreptomicetos testados foram eficientes em promover o crescimento e melhoria nutricional das mudas de tomateiro.

\section{REFERÊNCIAS}

BRIC, J. M.; BOSTOCK, R. M.; SILVERSTONE, S. E. Rapid in so assay for indolacetic acid production by bacteria immobility on a nitrocellulose membrane. Applied and Environmental Microbiology, Washington, v. 57, n. 2, p. 535-538, 1991.

CARMELLO, Q. A .C. Nutrição e adubação de mudas hortícolas. In: MINAMI, K. Produção de mudas de alta qualidade em horticultura. São Paulo: T. A. Queiroz, 1995. p. 27-37.

COMPANT, S. et al. Use of plant growth-promoting bacteria for biocontrol of plant diseases: principles, mechanisms of action, and future perspectives. Applied and Environmental Microbiology, Washington, v. 71, n. 9, p. 4951-4959, 2005.

COON, H. J.; JENNISON, M. W.; WEEK, O. B. Routine tests for the identification of bacteria. In: SOCIETY OF AMERICAN BACTERIOLOGISTS. Manual of microbiological methods. New York: McGraw-Hall, 1957. p. 239-262.

DING, C. H. et al. High activity xilanase production by Streptomyces olivaceoviridis E-86. World Journal of Microbiology and Biotechnology, Oxford, v. 20, n. 1, p. 7-10, 2004.

EMPRESA BRASILEIRA DE PESQUISA AGROPECUÁRIA (Embrapa). Manual de análises químicas de solos, plantas e fertilizantes. Brasília, DF: Embrapa Transferência de Tecnologia, 1999.

FERREIRA, D. F. Análises estatísticas por meio do Sisvar para Windows versão 4.0. In: REUNIÃO ANUAL DA REGIÃO BRASILEIRA DA SOCIEDADE INTERNACIONAL DE BIOMETRIA, 45., 2000, São Carlos. Anais... São Carlos: UFSCar, 2000. p. 255-258.

FILGUEIRA, F. A. R. Manual de oleiricultura: cultura e comercialização de hortaliças. São Paulo: Agronômica Ceres, 2000.

GORIELY, A.; TABOR, M. Biomechanical models of hyphal growth in actinomycetes. Journal of Theoretical Biology, London, v. 22, n. 2, p. 211-218, 2003.

GUIMARÃES, V. F.; ECHER, M. M.; MINAMI, K. Métodos de produção de mudas, distribuição de matéria seca e produtividade de plantas de beterraba. Horticultura Brasileira, Brasília, DF, v. 20, n. 3, p. 505-509, 2002. 
HOSTER, F.; SCHMITZ, J. E.; DANIEL, R. Enrichment of chitinolytic microorganisms: isolation and characterization of s chitinase exhibiting antifungical activity against phytopathogenic fungi from a novel Streptomyces strain. Applied Microbiology Biotechnology, Berlin, v. 66, n. 4, p. 434-442, 2005.

JAIN, P. K.; JAIN, P. C. Isolation, characterization and antifungal activity of Streptomyces sampsonii GS1322. Indian Journal of Experimental Biology, New Delhi, v. 45, n. 2, p. 203-206, 2007.

KATSIFAS, E. A.; KORAKI, T. G.; KARAGOUNI, A. D. Determination of metabolic activity of streptomycetes in soil microcosms. Journal of Applied Microbiology, Oxford, v. 89, n. 1, p. 178-184, 2000.

KATZNELSON, H.; BOSE, B. Metabolic activity and phosphate-dissolving capability of bacterial isolates from wheat roots, rhizosphere, and non-rhizosphere soil. Canadian Journal of Microbiology, Ottawa, v. 5, n. 1, p. 79-85, 1959.

LEWIS, K. J. Biological control mechanisms of the mycoparasite Phythium oligandrum Drechsler. 1988. $125 \mathrm{f}$. Tese (Doutorado em Plant Science)-University of Sheffield, Sheffield, 1988.

MONTEZANO, E. M.; PEIL, R. M. N. Sistemas de consórcio na produção de hortaliças. Revista Brasileira de Agrociência, Pelotas, v. 12, n. 2, p. 129-132, 2006.

OTONIANO, A. J.; FLORIAN, L. M.; SEVILLANO, R. B. La matéria orgânica: importância y experiência de su uso em la agricultura. Idesia, Arica, v. 24, n. 1, p. 49-61, 2006.

PADILHA, G. Biologia molecular de Streptomyces e aplicações industriais. In: MELO, I. S. de; AZEVEDO, J. L. Ecologia microbiana. Jaguariúna: Embrapa-CNPMA, 1998. p. 327-343.

PELÁEZ, F. The historical delivery of antibiotics from microbial natural products: can history repeat? Biochemical Pharmacology, London, v. 7, n. 7, p. 981990, 2006.

PETROSYAN, P. et al. Streptomyces mexicanus sp.: a xylanolytic micro-organism isolated from soil. Internacional Journal of Systematic and Evolutionary Microbiology, Reading, v. 53, n. 1, p. 269-273, 2003.
RENWICK, A.; CAMPBELL, R.; COE, S. Assessment of in vitro screening systems for potential biocontrol agents of Gaeumannomyces graminis. Plant Pathology, London, v. 40, n. 4, p. 524-532, 1991.

SHAHIDI BONJAR, B. G. H. et al. Broadspectrim: a novel antibacterial from Streptomyces sp. Biotecnology, Oman, v. 3, n. 2, p. 126-130, 2004.

SIERRA, S. A. Simple method for detection of lipolytic activity of microorganisms and some observations on the influence of the contact between cells and fatty substrates. Antonie van Leeuwenhoek, New York, v. 23, n. 1, p. 1522, 1957.

SOUSA, C. S.; SOARES, A. C. F.; GARRIDO, M. S. Produção de mudas de tomateiro em substrato orgânico infestado e incubado com estreptomicetos. Bragantia, Campinas, v. 68, n. 1, p. 195-203, 2009.

SPAEPEN, S.; VANDERLEYDEN, J.; REMANS, R. Indole-3-acetic acid in microbial and microorganism-plant signaling. FEMS Microbiology Reviews, Oxford, v. 31, n. 4, p. 425-448, 2007.

TEALE, W. D.; PAPONOV, I. A.; PALME, K. Auxin in action: signaling, transport and the control of plant growth and development. Nature Reviews Molecular Cell Biology, London, v. 7, n. 11, p. 847-859, 2006.

THIRUP, L.; JOHNSEN, K.; WINDING, A. Succession of indigenous Pseudomonas spp. and actinomycetes on barley roots affected by the antagonistic strain Pseudomonas fluorescens DR 54 and the fungicide imazolil. Applied and Environmental Microbiology, Washington, v. 67, n. 3, p. 1147-1153, 2001.

TSAVKELOVA, E. A. et al. Orchid-associated bacteria produce indole-3-aceticacid, promote seed germination, and increase their microbial yielding response to exogenous auxin. Archives of Microbiology, Paris, v. 188, n. 6, p. 655-664, 2007.

TUITE, J. Plant pathological methods: fungi and bacteria. Minneapolis: Burgess Publishing Company, 1969. 